\title{
Mean Amplitudes of Vibration of the $\mathrm{IF}_{8}{ }^{-}$Anion
}

\author{
Enrique J. Baran \\ Centro de Química Inorgánica (CEQUINOR/CONICET, UNLP), Facultad de Ciencias Exactas, \\ Universidad Nacional de La Plata, C. Correo 962, 1900 La Plata, Argentina
}

Correspondence should be addressed to Enrique J. Baran, baran@quimica.unlp.edu.ar

Received 4 September 2008; Accepted 25 November 2008

Recommended by Konrad Seppelt

The mean amplitudes of vibration of the interesting $\mathrm{IF}_{8}{ }^{-}$anion $\left(\mathrm{D}_{4 \mathrm{~d}}-\right.$ symmetry), containing iodine (VII), were calculated from known spectroscopic and structural data in the temperature range between 0 and $1000 \mathrm{~K}$. The results are discussed in comparison with those of related species.

Copyright () 2008 Enrique J. Baran. This is an open access article distributed under the Creative Commons Attribution License, which permits unrestricted use, distribution, and reproduction in any medium, provided the original work is properly cited.

\section{Introduction}

Mean amplitudes of vibration are very useful and valuable parameters for the analysis of molecular structures and their vibrational behavior. In a similar way to vibrational frequencies and force constants, they can be very characteristic values for both bonded and nonbonded atoms $[1,2]$.

During years we have calculated mean amplitudes of vibration for a large series of molecules and ions containing halogen-halogen or halogen-oxygen bonds (for a recent review cf. [3]) and in this paper we present the results of our calculations for the interesting $\mathrm{IF}_{8}{ }^{-}$anion, which vibrational-spectroscopic behavior was only very recently definitely clarified [4].

As it is well known, the structure of this anion is a practically perfect Archimedean square antiprism [5], constituting the unique example of an interhalogen species presenting this geometry, which structural peculiarities are similar to those of the few other known examples of homoleptic species of this type, namely, $\mathrm{ReF}_{8}{ }^{2-}, \mathrm{ReF}_{8}{ }^{-}, \mathrm{WF}_{8}{ }^{2-}, \mathrm{UF}_{8}{ }^{2-}$, and $\mathrm{XeF}_{8}{ }^{2-}$ $[6,7]$.

\section{Calculations}

The mean amplitudes of vibration were calculated with the method of the "characteristic vibrations" of Müller et al. [8] (cf. also $[2,9]$ ). The necessary vibrational-spectroscopic data were taken from the recent paper of Dixon et al. [4] and the geometrical parameters from the paper of Mahjoub and Seppelt [5].

\section{Results and Discussion}

The obtained results, in the temperature range between 0 and $1000 \mathrm{~K}$, are shown in Table 1. Regarding the nonbonded F. . F pairs, F...F (in plane) refers to the pairs within one hemisphere of the anion, whereas F . F F (betw. planes) refers to neighboring pairs belonging to different hemispheres.

The analysis of the so far available data of mean amplitude values for I-F bonds has shown that the extreme values lie between $0.0377 \AA$ (for $\mathrm{IF}_{6}{ }^{+}$) and $0.0602 \AA$ (for $\left.\mathrm{IF}_{5}{ }^{2-}\right)[3,10]$, in agreement with the fact that in the first case iodine presents the oxidation state +7 and a positive charge whereas in the other one the iodine is in the oxidation state +3 and not only presents two negative charges but also an important congestion effect on the molecular plane, in which the fluorine atoms are practically in contact [3, $10,11]$. Besides, these two species present also the greatest differences in bond lengths found in I/F species ( $1.75 \AA$ for $\mathrm{IF}_{6}{ }^{+}, 2.095 \AA$ for $\left.\mathrm{IF}_{5}{ }^{2-}\right)[3,12]$. Furthermore, the specially high mean amplitude value of $\mathrm{IF}_{5}{ }^{2-}$ is in good agreement with the very low force constant calculated for the I-F bonds in this anion (1.53 mdyn/ $\AA$ [11]).

The values of the mean amplitudes of vibration calculated for the I-F bonds of $\mathrm{IF}_{8}{ }^{-}$fall clearly into the mentioned 
TABle 1: Mean amplitudes of vibration (in $\AA$ ) for the $\mathrm{IF}_{8}{ }^{-}$anion in the temperature range between 0 and $1000 \mathrm{~K}$.

\begin{tabular}{lccc}
\hline$T(\mathrm{~K})$ & $\mathrm{u}_{\mathrm{I}-\mathrm{F}}$ & $\mathrm{u}_{\mathrm{F} \ldots \mathrm{F}}($ in plane $)$ & $\mathrm{u}_{\mathrm{F} \ldots \mathrm{F}}$ (betw. planes) \\
\hline 0 & 0.0426 & 0.062 & 0.072 \\
100 & 0.0426 & 0.062 & 0.072 \\
200 & 0.0433 & 0.064 & 0.079 \\
298.16 & 0.0455 & 0.069 & 0.089 \\
300 & 0.0456 & 0.069 & 0.089 \\
400 & 0.0487 & 0.075 & 0.099 \\
500 & 0.0521 & 0.082 & 0.109 \\
600 & 0.0556 & 0.088 & 0.118 \\
700 & 0.0590 & 0.094 & 0.127 \\
800 & 0.0624 & 0.100 & 0.135 \\
900 & 0.0656 & 0.105 & 0.143 \\
1000 & 0.0688 & 0.110 & 0.150 \\
\hline
\end{tabular}

TABle 2: Mean amplitudes of vibration (in $\AA$ ) of some iodine (VII) species at three different temperatures ((eq): equatorial I-F bonds; (ax): axial I-F bonds).

\begin{tabular}{lcccc}
\hline Species & $0 \mathrm{~K}$ & $298.16 \mathrm{~K}$ & $600 \mathrm{~K}$ & Reference \\
\hline $\mathrm{IF}_{6}{ }^{+}$ & 0.0367 & 0.0377 & 0.0433 & {$[13]$} \\
$\mathrm{IF}_{7}$ (eq) & 0.0408 & 0.0430 & 0.0516 & {$[14]$} \\
$\mathrm{IF}_{7}(\mathrm{ax})$ & 0.0378 & 0.0390 & 0.0454 & {$[14]$} \\
$\mathrm{IOF}_{6}{ }^{-}$(eq) & 0.0418 & 0.0444 & 0.0537 & {$[15]$} \\
$\mathrm{IOF}_{6}{ }^{-}(\mathrm{ax})$ & 0.0396 & 0.0414 & 0.0491 & {$[15]$} \\
$\mathrm{IO}_{2} \mathrm{~F}_{5}{ }^{2-}$ & 0.0455 & 0.0499 & 0.0625 & {$[16]$} \\
$\mathrm{IO}_{2} \mathrm{~F}_{4}{ }^{-}$ & 0.0421 & 0.0448 & 0.0544 & {$[17]$} \\
$\mathrm{IF}_{8}{ }^{-}$ & 0.0426 & 0.0455 & 0.0556 & this work \\
\hline
\end{tabular}

range as it can also be seen from the comparative data presented in Table 2. This comparison shows that the values for $\mathrm{IF}_{8}{ }^{-}$are appreciably higher than those found for $\mathrm{IF}_{6}{ }^{+}$ showing again the effect of the geometry and of the negative charge over bond weakening [3]. Besides, these amplitude values are only somewhat higher than those calculated for the equatorial $\mathrm{IF}_{7}$ bonds.

On the other hand, the values calculated for $\mathrm{IF}_{8}{ }^{-}$lie relatively close to those of the equatorial I-F-bonds of $\mathrm{IOF}_{6}{ }^{-}$. In comparison with the interhalogen bonds of the other two fluorooxoanions containing iodine (VII), $\mathrm{IF}_{8}{ }^{-}$presents lower mean amplitudes of vibration (i.e., stronger I-F bonds) than $\mathrm{IO}_{2} \mathrm{~F}_{5}{ }^{2-}$ but weaker I-F bonds than $\mathrm{IO}_{2} \mathrm{~F}_{4}{ }^{-}$, in the full temperature range.

Concerning the amplitude values of the nonbonded pairs, those of the same hemispheres are always lower and show a smaller temperature dependence than those between F-atoms belonging to the different hemispheres.

\section{Conclusions}

Mean amplitudes of vibration of the $\mathrm{IF}_{8}{ }^{-}$anion clearly lie in the expected range determined for I-F bonds. These values point to relatively weak bonds, when compared with iodine fluorine bonds present in other simple iodine (VII) species, such as $\mathrm{IF}_{7}$ or $\mathrm{IF}_{6}{ }^{+}$, in agreement with the higher coordination number and with the presence of a negative charge in the case of the $\mathrm{IF}_{8}{ }^{-}$anion.

\section{Acknowledgments}

This work has been supported by the Consejo Nacional de Investigaciones Científicas y Técnicas de la República Argentina (CONICET) and the Universidad Nacional de La Plata. The author is a member of the Research Career of CONICET.

\section{References}

[1] S. J. Cyvin, Molecular Vibrations and Mean Square Amplitudes, Elsevier, Amsterdam, The Netherlands, 1958.

[2] A. Müller, E. J. Baran, and K. H. Schmidt, "Characteristic mean amplitudes of vibration," in Molecular Structures and Vibrations, S. J. Cyvin, Ed., pp. 376-391, Elsevier, Amsterdam, The Netherlands, 1972.

[3] E. J. Baran, "Mean amplitudes of vibration of molecules and ions with interhalogen bonds and related species," Journal of Fluorine Chemistry, vol. 129, no. 11, pp. 1060-1072, 2008.

[4] D. A. Dixon, D. J. Grant, K. O. Christe, and K. A. Peterson, "Structure and heats of formation of iodine fluorides and the respective closed-shell ions from $\operatorname{CCSD}(\mathrm{T})$ electronic structure calculations and reliable prediction of the steric activity of the free-valence electron pair in $\mathrm{CIF}_{6}{ }^{-}, \mathrm{BrF}_{6}{ }^{-}$, and $\mathrm{IF}_{6}{ }^{-}, "$ Inorganic Chemistry, vol. 47 , no. 12 , pp. 5485-5494, 2008.

[5] A.-R. Mahjoub and K. Seppelt, "The Structure of $\mathrm{IF}_{8}{ }^{-}$," Angewandte Chemie International Edition in English, vol. 30, no. 7, pp. 876-878, 1991.

[6] S. Adam, A. Ellern, and K. Seppelt, "Structural principles of the coordination number eight: $\mathrm{WF}_{8}{ }^{2-}, \mathrm{ReF}_{8}{ }^{2-}$, and $\mathrm{XeF}_{8}{ }^{2-}$," Chemistry-A European Journal, vol. 2, no. 4, pp. 398-402, 1996.

[7] I.-Ch. Hwang and K. Seppelt, "The structures of $\mathrm{ReF}_{8}{ }^{-}$and $\mathrm{UF}_{8}{ }^{2-}$," Journal of Fluorine Chemistry, vol. 102, no. 1-2, pp. 69-72, 2000.

[8] A. Müller, C. J. Peacock, H. Schulze, and U. Heidborn, "An approximate method for the calculation of mean amplitudes of vibration in complex molecules," Journal of Molecular Structure, vol. 3, no. 3, pp. 252-255, 1969.

[9] E. J. Baran, "Amplitudes medias de vibración del cloruro de cromilo," Anales de la Asociación Química Argentina, vol. 61, pp. 141-151, 1973.

[10] E. J. Baran, "Peculiarities of I-F and I-O bonds in different hypervalent species of iodine," The Journal of the Argentine Chemical Society, vol. 93, no. 4-6, pp. 23-27, 2005.

[11] K. O. Christe, W. W. Wilson, G. W. Drake, D. A. Dixon, J. A. Boatz, and R. Z. Gnann, "Pentagonal planar $\mathrm{AX}_{5}$ species: synthesis and characterization of the iodine(III) pentafluoride dianion, $\mathrm{IF}_{5}{ }^{2-}$," Journal of the American Chemical Society, vol. 120 , no. 19 , pp. 4711-4716, 1998.

[12] J. A. Boatz, K. O. Christe, D. A. Dixon, et al., "Synthesis, characterization, and computational study of the trans $-\mathrm{IO}_{2} \mathrm{~F}_{5}{ }^{2-}$ anion," Inorganic Chemistry, vol. 42, no. 17, pp. 5282-5292, 2003.

[13] E. J. Baran, "Mittlere Schwingungsamplituden von $\mathrm{JF}_{6}{ }^{+}$, Monatshefte für Chemie, vol. 105, no. 5, pp. 1148-1150, 1974. 
[14] E. J. Baran, "Mean amplitudes of vibration for the isoelectronic series $\mathrm{TeF}_{7}{ }^{-}, \mathrm{IF}_{7}$ and $\mathrm{XeF}_{7}{ }^{+}$," Journal of Molecular Structure, vol. 351, pp. 211-214, 1995.

[15] E. J. Baran, "Mean amplitudes of vibration of the pentagonal bipyramidal $\mathrm{TeOF}_{2}{ }^{2-}$ anion," Anales de la Asociación Química Argentina, vol. 83, no. 3-4, pp. 207-209, 1995.

[16] E. J. Baran, "Mean amplitudes of vibration of the trans$\mathrm{IO}_{2} \mathrm{~F}_{5}{ }^{2-}$ anion," Zeitschrift für Naturforschung, vol. 59a, no. 7-8, pp. 527-528, 2004.

[17] E. J. Baran, "Mean amplitudes of vibration of the trans$\mathrm{IO}_{2} \mathrm{~F}_{5}{ }^{2-}$ anion," Zeitschrift für Naturforschung, vol. 59a, pp. 877-878, 2004. 


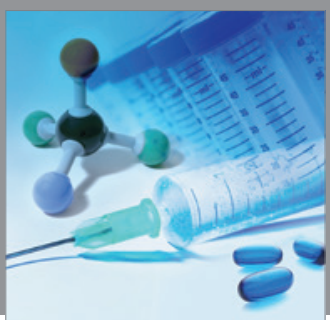

International Journal of

Medicinal Chemistry

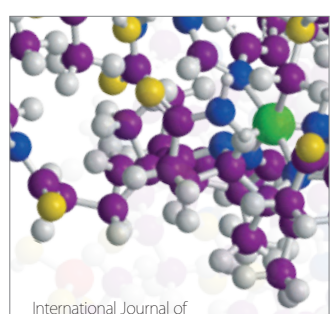

Carbohydrate Chemistry

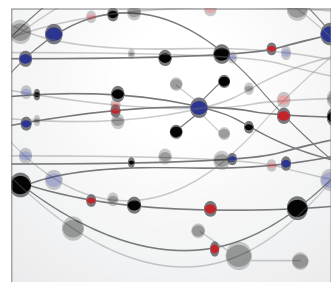

The Scientific World Journal
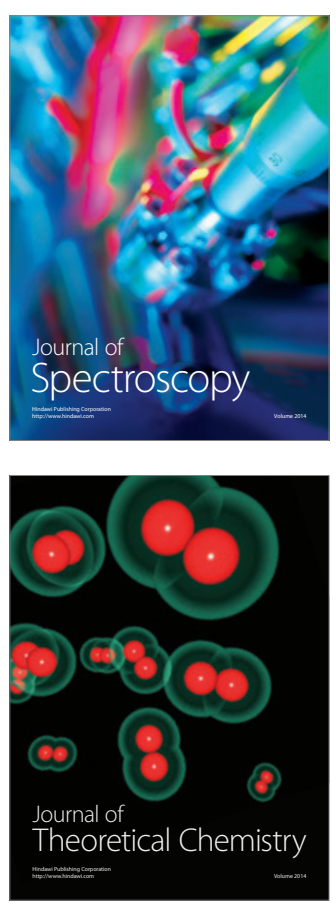
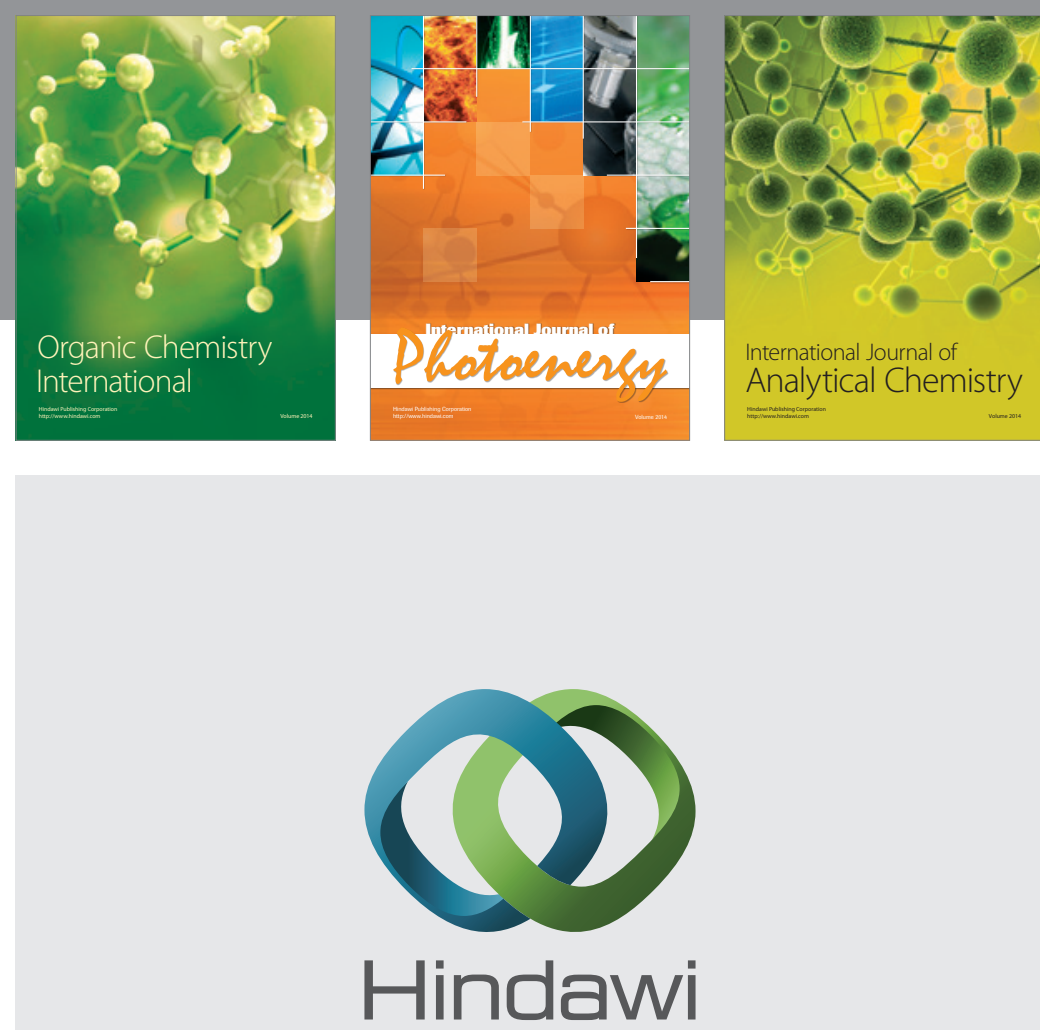

Submit your manuscripts at

http://www.hindawi.com
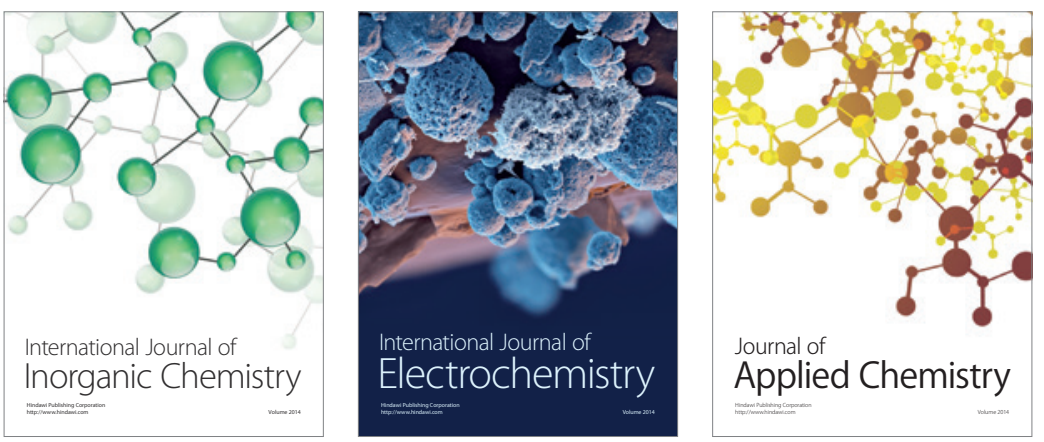

Journal of

Applied Chemistry
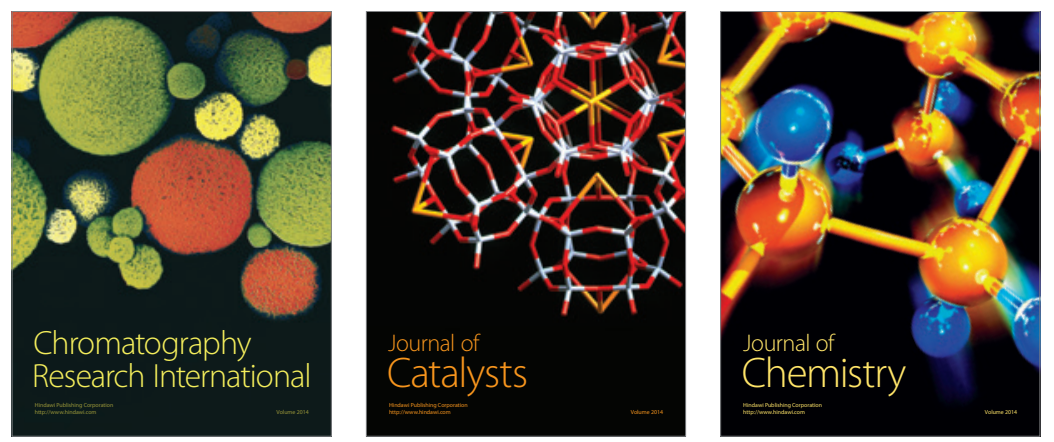
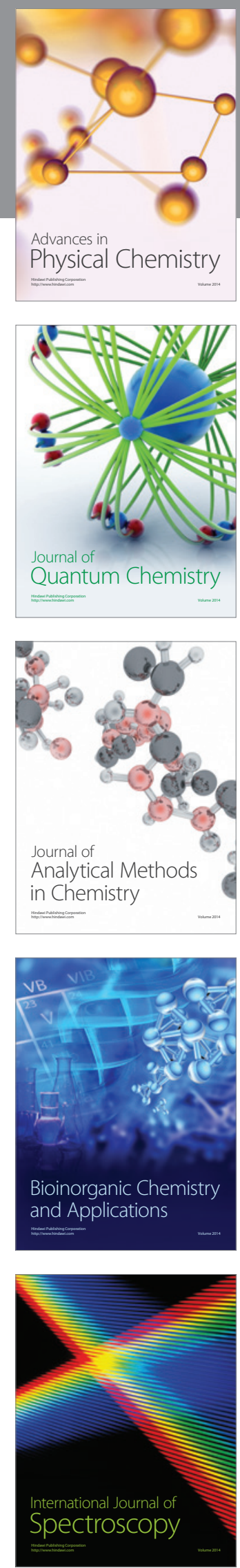